\title{
Selective perimeter lockdowns in Madrid: a way to bend the COVID-19 curve?
}

Mario Fontán-Vela, MD MPH ${ }^{1,2}$, Pedro Gullón MD MPH PhD 2,3, Javier Padilla-Bernáldez $\mathrm{MD} \mathrm{MPH}{ }^{3,4}$

1. Servicio de Medicina Preventiva, Hospital Universitario Infanta Leonor, Madrid, Madrid, Spain

2. Public Health and Epidemiology research group, School of Medicine and Health Sciences, Universidad de Alcalá, Alcalá de Henares, Madrid, Spain

3. Colectivo Silesia, Spain

4. Fuencarral Primary Health Care Center, Madrid, Spain

\section{Corresponding autor:}

Mario Fontán-Vela MD MPH

Email: mario.fontan@edu.uah.es

Address: Facultad de Medicina y Ciencias de la Salud, Universidad de Alcalá. Crta Madrid-Barcelona km 33,600, 28871 Alcalá de Henares, Madrid, Spain Phone: +34 617991788

\begin{abstract}
Lockdowns have been widespread used to limit social interaction and bend the epidemic curve. However, their intensity and geographical delimitation have been variable across different countries. Madrid (Spain) implemented perimeter lockdowns in September with the purpose of bending the COVID-19 curve. In this paper we compared, using join point regressions, the evolution of COVID-19 cases in those areas where this intervention was implemented and those where it was not. According to our analysis, the decrease in the epidemic curve started before the impact of the perimeter lockdown could be reflected.
\end{abstract}

Keywords: COVID-19, SARS-CoV-2, pandemics, non-pharmaceutical intervention, lockdown. 


\section{Introduction}

The use of interventions aiming to limit mobility and economic activity has been a widespread non-pharmaceutical intervention (NPI) to control the transmission of SARSCoV-2. ${ }^{1}$ Lockdown interventions have been seen as one of the most effective ways to bend the epidemic curve. ${ }^{2}$ However, their intensity and geographical delimitation have been variable. Thus, an individual evaluation of each strategy is required to determine their effectiveness in order to design future NPI to mitigate the effect of COVID-19 transmission. ${ }^{3}$

Madrid is one of the most affected european regions throughout the pandemic, and the spanish region with the highest number of cases and deaths: until December 16th, 369,522 COVID-19 cases and 11,619 deaths have been declared, meaning an estimated seroprevalence of $18.6 \%$ since the beginning of the pandemic, as shown in a recent report ${ }^{4}$. One study showed that Madrid was the spanish region with the largest drop in weekly life expectancy during the first wave of the pandemic ${ }^{4}$.

In September 21st, in the middle of the second wave of the pandemic, Madrid regional government implemented the so-called "perimeter lockdowns" in the Basic Health Zones $(\mathrm{BHZ})^{6}$ (the smallest health territorialization units, composed of a mean population of 22,290 inhabitants) where community transmission was reaching critical levels (14-day COVID-19 cases rate per $100,000>1,000$ on September 15th). This perimeter lockdowns restricted mobility in-and-out of the $\mathrm{BHZ}$ except for essential purposes (work or academic activities, caring for dependent people or carrying out administrative procedures) as well as limited capacity of business but without closing restaurants or restricting other types of economic activity. This type of lockdown was only comparable to the "dynamic confinements" in Chile, whose effectiveness has been questioned". Thus, we want to assess whether the trend of 14-day COVID-19 rate changed in the $\mathrm{BHZ}$ affected by perimetral lockdown with respect to other $\mathrm{BHZ}$ in the city of Madrid that were not affected by the perimetral lockdown. 


\section{Methods}

Data source

We collected publicly available weekly data on the 14-day COVID-19 rate per 100,000 population between July 7th and 1st December from the open COVID-19 open portal dataset of the Health Department of the regional government.

First, we selected all $\mathrm{BHZ}$ within the city of Madrid, excluding the rest of the region to avoid the potential bias of the rural areas. From this, we selected the $26 \mathrm{BHZ}$ that were affected by the perimeter lockdowns and a control group of $29 \mathrm{BHZ}$ that had a 14-day COVID-19 rate above 700 cases per 100,000 on September 15th (when first perimeter lockdown was decided). We chose this cut-off point for the control group in order to have a comparable group in terms of similar COVID-19 transmission at the time of the lockdown decision.

\section{Statistical analysis}

We conducted a descriptive analysis of the trends of 14-day COVID-19 rate of the city of Madrid, and the $\mathrm{BHZ}$ within the city with and without the perimeter lockdown implemented.To identify changes in 14-day COVID-19 rate trends, joinpoint analysis was performed for the entire city of Madrid. Secondly, the same analysis was performed separately for those $\mathrm{BHZ}$ with and without perimeter lockdown. The time period of analysis comprises between July 7th and 1st December. The software used was the Joinpoint Trend Analysis, Version 4.8.0.1 (Statistical Research and Applications Branch, National Cancer Institute).

\section{Results}

In the city of Madrid, the 14-day COVID-19 rate increased in the second wave until a maximum peak of 770.5 cases per 100,000 inhabitants on September 22nd (Figure 1). Three join points were described, delimiting four periods for the epidemic curve of the city of Madrid (Figure 1; Supplementary File 1): Jul 7th-Jul 21st, Jul 21st-Aug 18th, Aug 
18th-Sep 15th, and Sep 15th onwards. The first three periods showed 14-day COVID19 rate weekly increases: $5.45 \%, 111.42 \%$, and $31.68 \%$ respectively. However, the last one showed a $11.10 \%$ weekly decrease. A similar pattern was observed in the $\mathrm{BHZ}$ without perimeter lockdown: the first three periods experienced weekly increases $(10.89 \%, 112.42 \%$, and $31.05 \%)$, but the trend started to decline on September 15 th (11.52\% weekly decrease). For the $\mathrm{BHZ}$ affected by perimeter lockdowns, four join points were described, delimiting five trend periods: Jul 7th-Jul 21st, Jul 21st-Aug 25th, Aug 25th-Sep 22nd, Sep 22nd-Oct 20th, and Oct 20th-Dec 1st. The first three periods showed weekly increases: $12.03 \%, 116.79 \%$, and $9.94 \%$ respectively. The last two periods experienced weekly decreases: $22.05 \%$ and $11.34 \%$.

\section{Discussion}

In this analysis, we identified trend changes in the 14-day COVID-19 rate in Madrid using a joinpoint analysis in order to identify if these changes are associated with the selective perimeter lockdowns implemented on September 22nd. The change in the COVID-19 rate trend occurred around the 15th for the entire city of Madrid and the $\mathrm{BHZ}$ not affected by the perimeter lockdown, and around the 22th for those $\mathrm{BHZ}$ with perimeter lockdown implemented. Considering the incubation period and notification delay, it is required a minimum of 6-9 day lag period since the implementation of a NPI to detect any potential effect $^{8}$. Our results showed that the decrease in the epidemic curve, both in the entire city and the $\mathrm{BHZ}$ of the analysis, started before the impact of the perimeter lockdown could be reflected. Also, our results showed that the perimeter lockdowns did not increase the velocity at which cases were decreasing. Thus, the observed decrease might be associated with other NPI implemented in previous weeks, such as social meetings limitation, night clubs closure, or restaurant capacity limitation.

There are many reasons why perimeter lockdowns seemed not effective in reducing COVID-19 cases. First, the curve started to decrease before measures were taken. Second, perimeter lockdowns were focused on mobility rather than preventing high-risk 
situations (e.g. indoor activities ${ }^{9}$ ). Third, mobility was allowed for essential activities such as working, which represent most of the mobility of residents living in the affected $\operatorname{areas}^{10}$. Fourth, boundaries of $\mathrm{BHZ}$ were unknown to many residents, as they are used just for healthcare territorialization. As it has been discussed regarding the Chilean experience, the "spillover" effect of neighboring areas that are not under lockdown limits its potential effectiveness in high-interconnected cities $^{7}$.

This analysis has some limitations. First, our area-level analysis is sensible to ecological fallacy. Second, there are potential unmeasured confounders that were not under control (e.g. changes in personal awareness or personal attitudes). Third, there is a potential bias due to notification delay, which is more likely to happen when COVID-19 cases are higher.

The perimeter lockdown implemented during the peak of the second wave had no effect in the COVID-19 rate trend. Evaluation of NPI is key to elucidate its effectiveness to control the SARS-CoV-2 transmission, and to gather relevant information to design policies during a public health emergency.

\section{Funding}

PG was supported by the European Union's Horizon 2020 research and innovation program under the Marie Sklodowska-Curie grant agreement No 842957. The funding agencies had no involment in the study design; in the data collection, analysis or interpretation of data; in the writing of this work; or in the decisión to submit the manuscript for publication.

\section{Conflicts of interest}

The authors declare no conflicto of interest 


\section{Key-points}

- NPI effectiveness evaluation is necessary for a better response during public health emergencies.

- Lockdown implementation should be adapted to the social patterns of mobility in urban settings.

- Public health measures during pandemics should consider not only factors related to mobility but also high-risk transmission activities.

References:

1. Kucharski AJ, Klepac P, Conlan AJK, Kissler SM, Tang ML, Fry H, et al. Effectiveness of isolation, testing, contact tracing, and physical distancing on reducing transmission of SARS-CoV-2 in different settings: a mathematical modelling study. The Lancet Infectious Diseases.2020;20(10):1151-60.

2. Flaxman S, Mishra S, Gandy A, Unwin HJT, Mellan TA, Coupland H, et al. Estimating the effects of non-pharmaceutical interventions on COVID-19 in Europe. Nature.2020;584(7820):257-61.

3. Karatayev VA, Anand M, Bauch CT. Local lockdowns outperform global lockdown on the far side of the COVID-19 epidemic curve. PNAS.2020;117(39):24575-80.

4. Instituto de Salud Carlos III, Ministerio de Sanidad. Estudio ENE-COVID: Cuarta ronda. Estudio de sero-epidemiología de la infección por SARS-CoV-2 en España. 15 de diciembre de 2020. [Internet] Available from: <https://www.lamoncloa.gob.es/serviciosdeprensa/notasprensa/sanidad14/Doc uments/2020/151220_informe_definitivo_cuarta_ronda_enecovid.pdf > [Accessed 16 December 2020].

5. Trias-Llimós S, Riffe T, Bilal U. Monitoring life expectancy levels during the COVID-19 pandemic: Example of the unequal impact of the first wave on Spanish regions. PLoS ONE. 2020;15(11):e241952. DOI: 10.1371/journal.pone.0241952. 
6. ORDEN 1178/2020, de 18 de septiembre, de la Consejería de Sanidad, por la que se adoptan medidas específicas temporales y excepcionales por razón de salud pública para la contención del COVID-19 en núcleos de población correspondientes a determinadas zonas básicas de salud, como consecuencia de la evolución epidemiológica. Boletín Oficial de la Comunidad de Madrid: Comunidad de Madrid; 2020.

7. Li Y, Undurraga EA, Zubizarreta JR. Effectiveness of Localized Lockdowns in the SARS-CoV-2 Pandemic. medRxiv.2020;2020.08.25.20182071.

8. Li, Y., Campbell, H., Kulkarni, D., Harpur, A., Nundy, M., Wang, X. and Nair, H., 2020. The temporal association of introducing and lifting non-pharmaceutical interventions with the time-varying reproduction number $(\mathrm{R})$ of SARS-CoV-2: a modelling study across 131 countries. The Lancet Infectious Diseases, p.[Epub ahead of print].

9. Chang S, Pierson E, Koh PW, et al. Mobility network models of COVID-19 explain inequities and inform reopening. Nature 2020; published online Nov 10. DOI:10.1038/s41586-020-2923-3.

10. Grupo de Investigación en Arquitectura, Urbanismo y Sostenibilidad, 2020. Movilidad y segunda ola en las áreas urbanas. ¿Dónde trabaja la población de las 37 zonas "confinadas" de Madrid?. [Internet] Available from: <https://www.upm.es/?id=ced85b856bfb4710VgnVCM10000009c7648a__\&p refmt=articulo\&fmt=detail> [Accessed 9 December 2020]. 
Figures

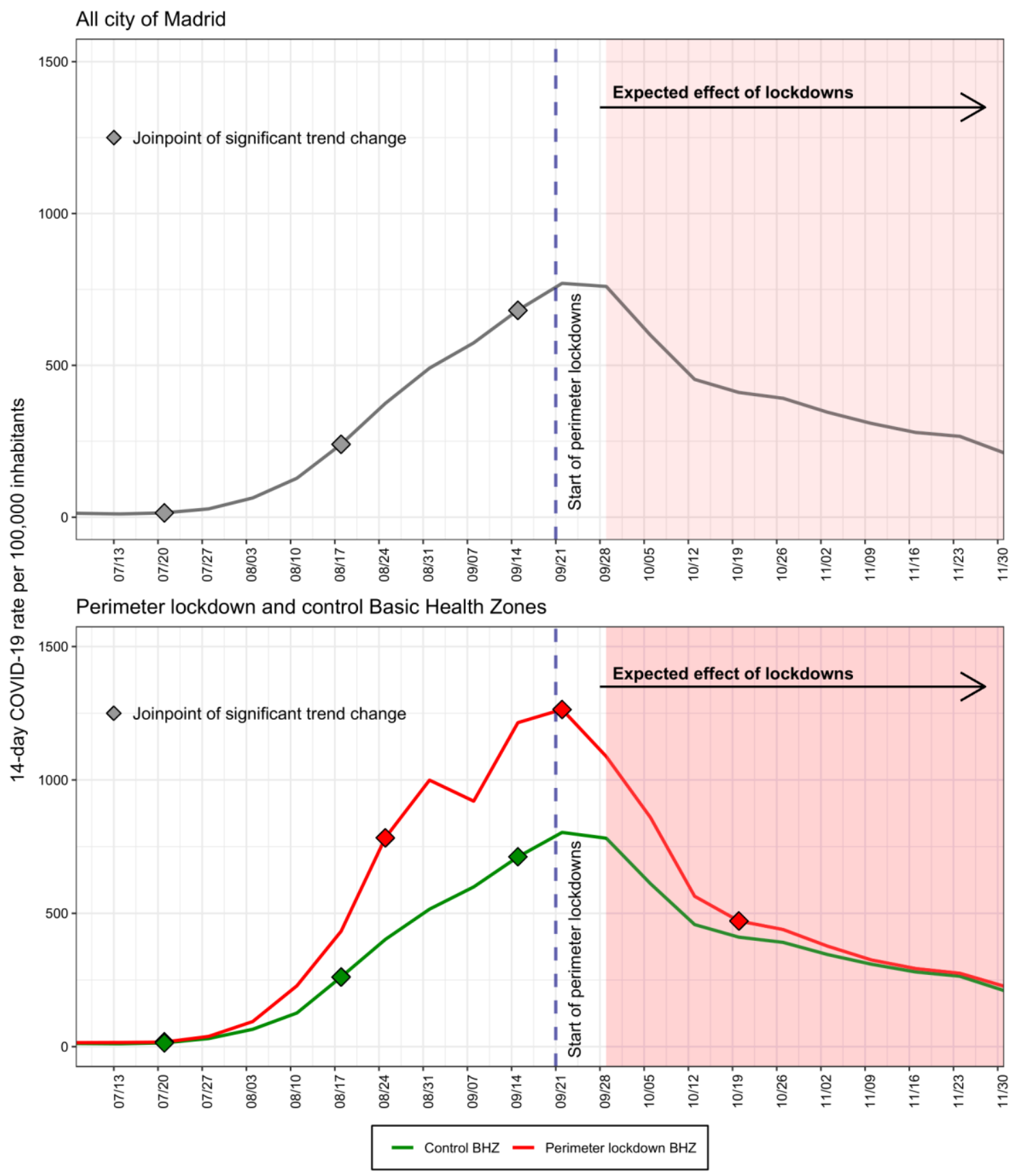

Figure 1: 14-day COVID-19 rate from July 7th to December 1 st in the whole city of Madrid (upper panel) and the Basic Health Zones (BHZ) affected by perimeter lockdowns and control $\mathrm{BHZ}$ not affected by perimeter lockdowns (down panel). 
City of Madrid: All: 3 Joinpoints

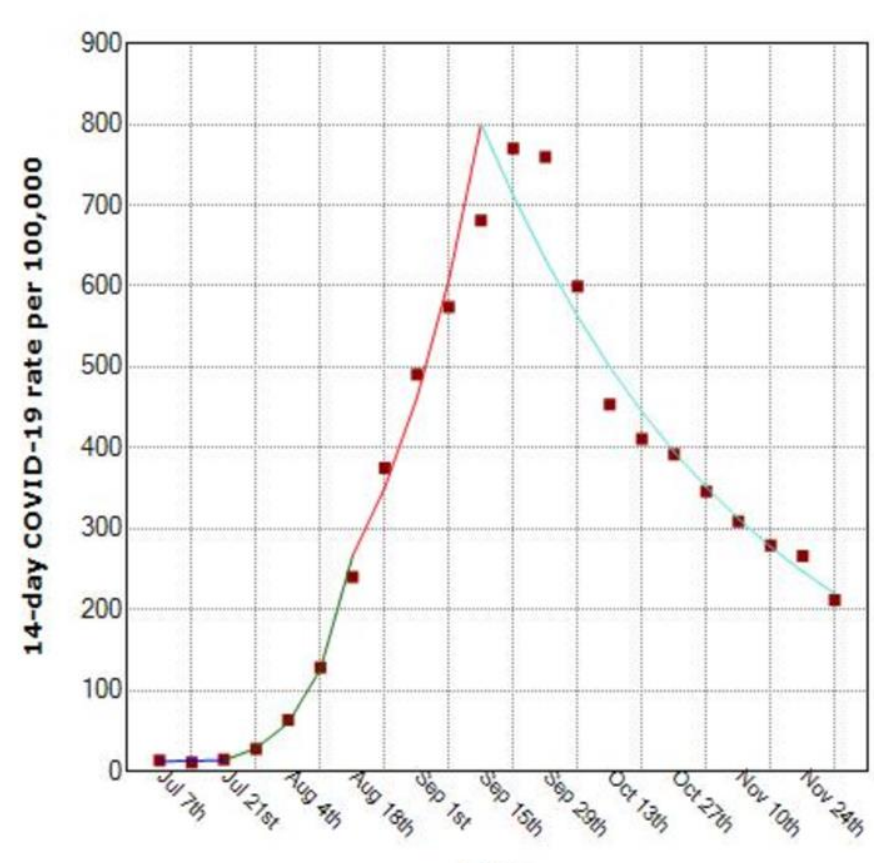

Date

- Indicates that the Annual Percent Change (APC) is significantly different from zero at the alpha $=0.05$ level Final Selected Model: 3 Joinpoints.

Figure S1: Join point regression of the 14-day COVID-19 rate from July 7 th to Decembter 1st in the whole city of Madrid. 


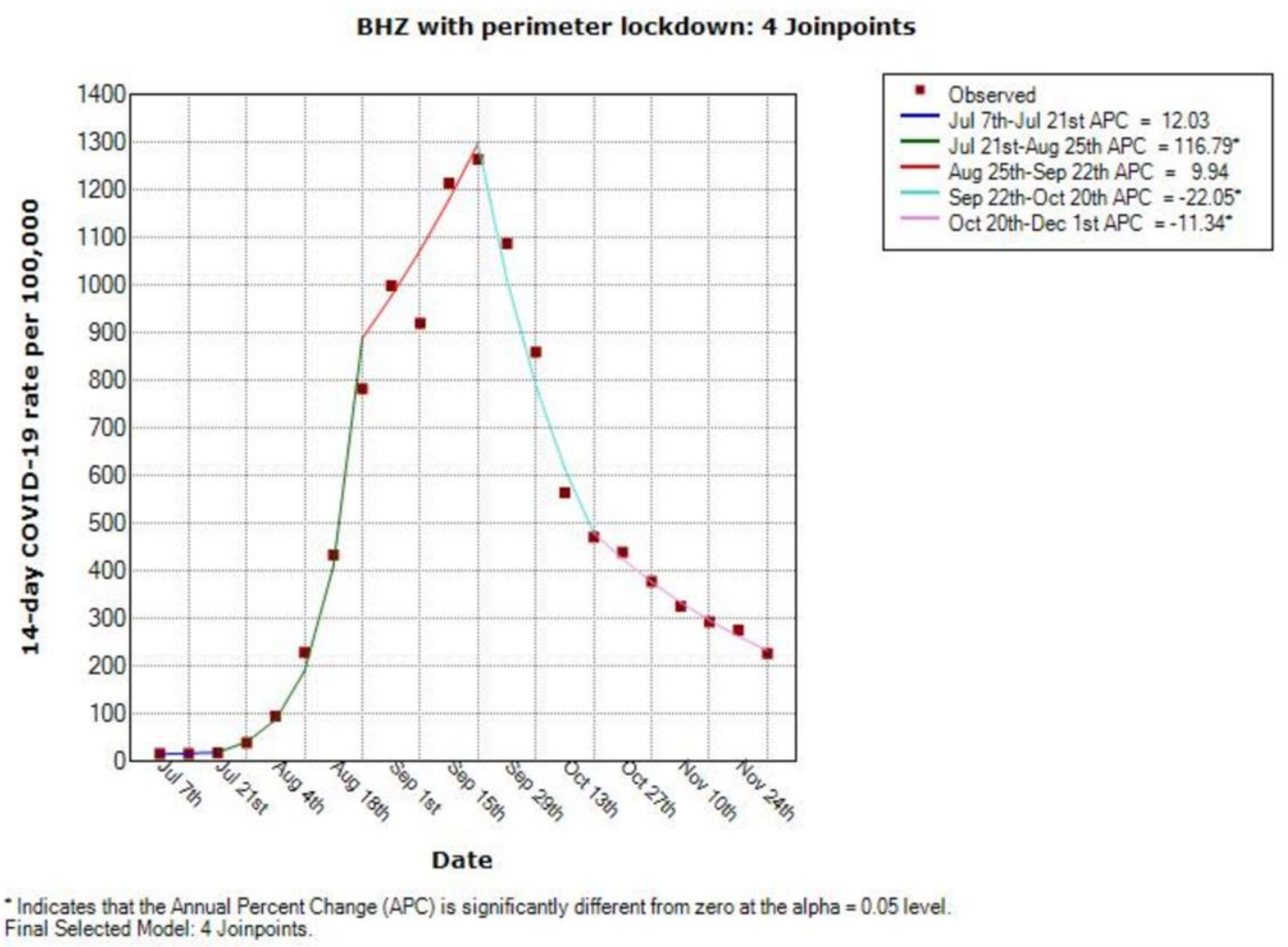

Figure S2: Join point regression of the 14-day COVID-19 rate from July 7 th to Decembter 1st in the Basic Health Zones (BHZ) affected by perimeter lockdowns. 


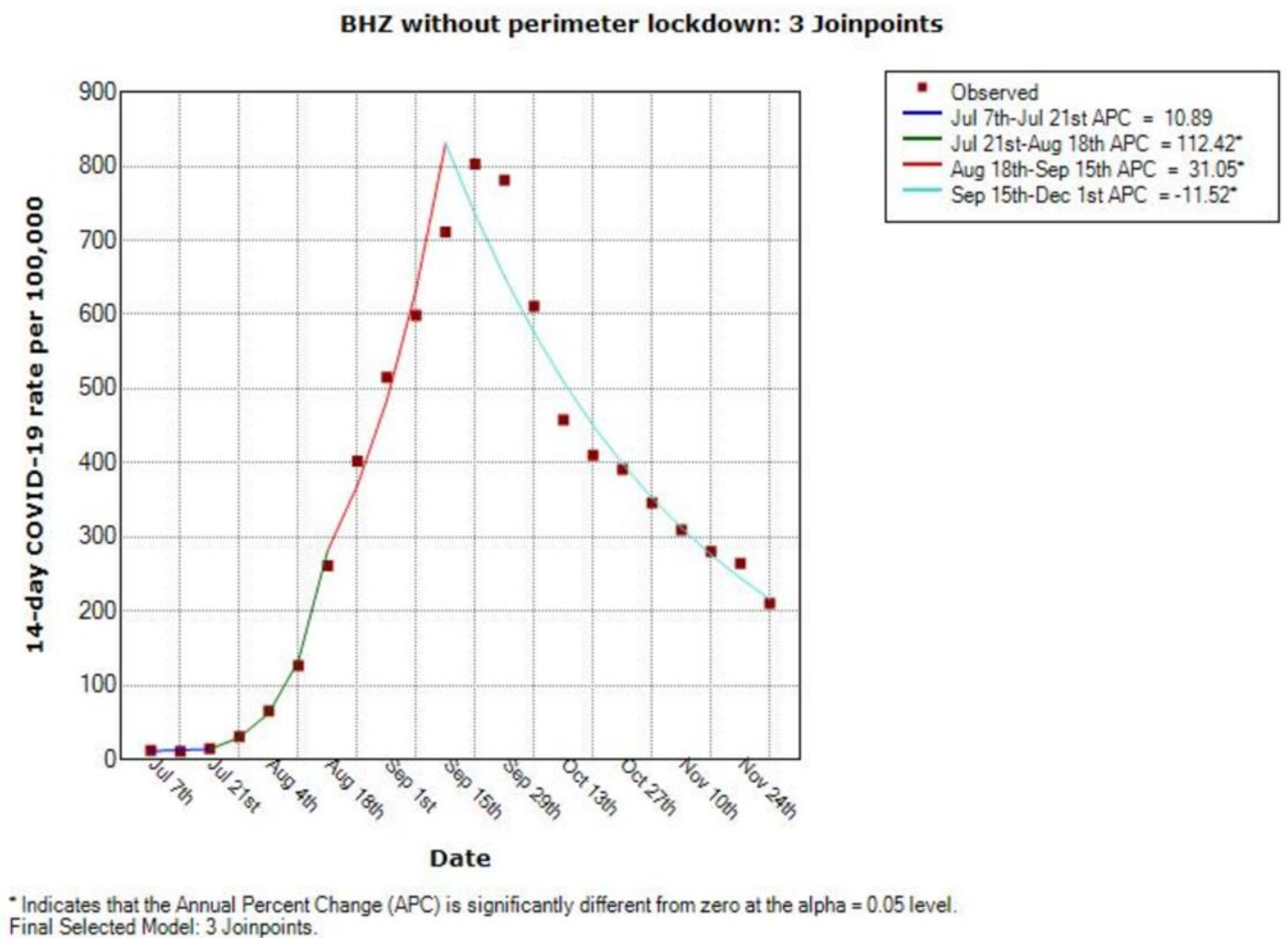

Figure S3: Join point regression of the 14-day COVID-19 rate from July 7 th to Decembter 1st in the control Basic Health Zones $(\mathrm{BHZ})$ not affected by perimeter lockdowns. 